\title{
Seismic Retrofitting Resilience-Based for Strategic RC Buildings
}

\author{
Marco Vona *D, Amedeo Flora (D), Emiliano Carlucci and Enrico Foscolo \\ School of Engineering, University of Basilicata, 85100 Potenza, Italy; amedeo.flora@unibas.it (A.F.); \\ emiliano.carlucci@unibas.it (E.C.); enrico.foscolo@unibas.it (E.F.) \\ * Correspondence: marco.vona@unibas.it; Tel.: +39-0971-205-063
}

\begin{abstract}
The resilience of communities is given by the ideal convolution of the resilience of all their single parts. Strategic buildings require high levels of performance during and after a seismic sequence. Consequently, the seismic retrofitting of old strategic buildings is a central issue in prevention and mitigation strategies. The core of the study is a resilience approach to the seismic retrofitting of existing strategic buildings. Different performance levels are considered and four different retrofitting techniques are compared according to their fragility, and their post-earthquake cost and time recovery analyses. Lastly, the retrofitting techniques are compared based on the considered resilience index, which in turn is related to the estimated reduction of the seismic losses owing to the different retrofitting techniques, but especially to the effectiveness of the intervention based on the relevant cost and recovery times. In other words, these aspects take into account the key role of a building's characteristics, and its public and strategic role during and after an earthquake. The intervention is selected not only (as is currently done) to reduce its construction times and costs, but to limit the service interruption after earthquakes. The results of this study could be operatively used as support tools in the seismic retrofitting of strategic buildings, either individually or on a large territorial scale.
\end{abstract}

Citation: Vona, M.; Flora, A.;

Carlucci, E.; Foscolo, E. Seismic Retrofitting Resilience-Based for Strategic RC Buildings. Buildings 2021, 11, 111. https://doi.org/ 10.3390/buildings11030111

Academic Editors: Alessandra Aprile and Giorgio Monti

Received: 4 February 2021

Accepted: 2 March 2021

Published: 11 March 2021

Publisher's Note: MDPI stays neutral with regard to jurisdictional claims in published maps and institutional affiliations.

Keywords: seismic risk mitigation; strategic building; seismic losses; resilient quantitative approach; resilience index

\section{Introduction}

In the medium to long term, the massive effects of any recent earthquake are strongly linked to the seismic performance of existing buildings and their recovery time. In particular, existing reinforced concrete buildings designed without seismic criteria or considering old seismic codes have played an important role. Following the recent research trends [1], it is evident that the major effects are connected to the low or absent resilience of the communities, the network and the single infrastructures [2]. Therefore, the high direct and indirect losses and the consequent long recovery times are no longer acceptable for the application of an actual resilience-based mitigation strategy. In the medium to long term, the consequences are evident in terms of homelessness, the downtime and the resources needed for the reconstruction process [3].

The resilience of communities is given by the ideal convolution of the resilience of all their single parts. Among these, the structures and infrastructures represent important elements in the resilience response. Based on their role during and after the seismic events, these buildings can be classified as strategic buildings. In the Italian and European codes, buildings are classified in four classes. They depend on the following topics: the consequences of collapse for human life, importance for public safety and civil protection, and the social and economic consequences of collapse. Commonly, the strategic buildings are classified in Importance class III or Importance class IV. Besides the importance class of each building, the importance factors are defined, but the assessment procedures (methods of analysis, structural modeling, safety verifications, knowledge process, and so on) are the same. Extensive scientific literature is available and partially reported in the study. 
Strategic buildings must attain high performance levels (PLs) during and after a seismic sequence. Therefore, the seismic retrofitting of old strategic buildings is a central issue in the prevention and mitigation strategies.

Historically, the choice of the retrofitting intervention was limited to the technical strategy, at best considering only the economic aspect. In fact, in some proposals, the retrofitting intervention was selected on the basis of a simple cost-benefit analysis, using the evaluation of the average annual frequency of losses (EAL), with more or less accurate methodologies $[4,5]$.

Some studies are only qualitative proposals, difficult or not applicable to real cases. For example, the considered relationships between response parameters (commonly called engineering demand parameters (EDP)) and damage models (DM) are inaccurate. On the other hand, specific functions for specific and regional relations and functions must be considered [6]. Currently, based on the accurate and available methods, too many simplified methods should not be applied (for example, those based on an expert approach for the evaluation of the repair costs).

In Italy, based on the concept of assigning a seismic class for each building (depending on the EAL), a simple method [7] has been proposed and applied to evaluate seismic losses using a simplified procedure. This method could be overcome by using more accurate risk indicators [8], based on accurate and easily implemented procedures that select the optimal intervention strategies. Globally, in too many studies and operative proposals, the optimal solution is based on the cost-benefit ratio (comparing the total loss and the cost of the investment). In seismic engineering, the cost-benefit analysis is not always appropriate and exhaustive.

A significant initial overcoming of the above limit can be obtained with the use of multi-criteria decision methods (MCDMs). In recent studies, MCDMs have been applied to the stock of buildings and single structures $[9,10]$, so as to define a prioritization list, or for the selection of the intervention strategies. In this way, each decision maker can use qualitative and quantitative criteria (that are not directly comparable) to define the optimal solution.

Nevertheless, the actual improvement in prevention and mitigation strategies could be represented by the resilience-based interventions. In recent years, the concepts of resilience have been progressively applied to seismic engineering, and significant proposals have been made [11-13] as basic definitions for the application of resilience concepts.

On a large territorial scale, the applications have often been carried out with interesting results. In actual fact, a community becomes truly resilient if all its parts are resilient. In this regard, there are some excellent initiatives [14] that provide for direct and targeted interventions on individual buildings. Interesting proposals and results have been reported in recent applications of resilience concepts [15-21]. However, it is necessary to develop and concretely apply the resilience concepts both for decision makers [22,23] and for the practice of professional applications. Some interesting applications have already been presented [24].

This work shows the results of a specific study on a strategic building, and demonstrates a simple and professional practice for the application of the concepts of resilience. For this, simple and well-established analysis tools have been considered to define a resilience-based approach to select the best retrofitting strategies. The proposal improves on the previous study [25] and is useful to be considered in a refined economic resilience framework that includes specific resilience strategies $[23,26]$.

\section{Methodology}

In this study, the considered framework is very simple and can be considered as a development of previous studies. The final goal is to identify the best seismic intervention strategy for a single strategic building. To this end, the resilience index is considered. The evaluation and comparison of the resilience index for the study of the building in its current and post-retrofit state (with different techniques) allows for the identification of the best 
solution. The assessments are based on specific fragility curves, cost analysis, and recovery times for the current and post-retrofit state with the considered intervention techniques. The evaluation of the losses, consequent costs, and time is carried out considering an accurate knowledge process. Consequently, functionality curves are defined, and the resilience increase is evaluated for the single parts of the resilience curves so as to simplify the decision maker's activities.

\subsection{Fragility Analysis}

Besides the seismic performance assessment of the existing buildings, an analytical approach has also been developed and widely applied. Currently, two main methodologies are considered: the building-based vulnerability assessment (BVA, [27]) based on a probabilistic approach, and the component-based vulnerability assessment (CVA, [14,28]) based on expert judgment or empirical data.

In the BVA approach, vulnerability curves are defined by the fragility curves (FCs) and analytical cost ratio (CR) functions. The analytical FCs are the optimal solution for seismic risk analyses both on a wide territorial scale and for single buildings. The accuracy of FCs is based on the models, the building information (global and local factors, material properties, structural details, etc.), the accuracy of the analysis [29], and the intra-building variability. The FCs are based on an engineering demand parameter (EDP), which is defined based on the connections between the considered damage level and a specific threshold. These thresholds and consequent connections are commonly called damage models (DM). The considered damage models play a key role in the development of the fragility curves and must be derived based on specific data from an investigated building type (for example, the design and construction practices, codes, etc.). In this study, the expert judgments are totally rejected both in the threshold evaluation and in the cost assessment. A more accurate and well consolidated approach is considered [6].

Lastly, vulnerability curves are developed based on accurate numerical analyses, whereby a set of cost ratio distributions is derived from the evaluated damage level and the damage analysis at the component level.

\subsection{Resilience}

To achieve a resilient building, the concepts of resilience must be contemplated in the selection of the intervention strategies. These activities should replace the current civil engineering practices; the proposed procedure is useful for any building type, particularly for strategic buildings due to their importance for public safety and civil protection. The real and practical application of the resilience concepts are based on the quantitative methods of resilience. This strategy must be based on the following objectives:

- Reduction of the seismic damage;

- Reduction of the recovery time;

- Reduction or annulment of the downtime (interruption of activities) to protect the economic activities.

However, to evaluate and operationally use seismic resilience, the approach is to be based on the following steps:

1. Selection of the seismic events;

2. Evaluation of the seismic vulnerability;

3. Performance evaluation in terms of damage for each performance level, restoration time, and resilience index;

4. Comparison of the different intervention techniques based on the resilience index.

The core of the proposal is the application of the resilience index, which is drawn from a combination of the resilience at different performance levels and the provision of the code. Conceptually, the considered resilience index is consistent with previous studies [22,23], wherein the resilience of the communities is derived from a combination of the resilience 
levels for the building types in specific areas (at the urban scale). Consequently, in this study the resilience index of a single building is defined, where the resilience is quantified as:

$$
\mathrm{R}_{\text {index }}(\mathrm{I})=\sum_{\mathrm{PL}=1}^{\mathrm{n}}\left\{\mathrm{W}_{\mathrm{PL}} \times\left(1-\frac{\mathrm{E}\left[\mathrm{T}_{\mathrm{RB}} \mid \mathrm{C}_{\mathrm{r}, \mathrm{r}}\right]}{\mathrm{T}_{\mathrm{LC}}} \times \mathrm{E}\left[\mathrm{C}_{\mathrm{r}, \mathrm{r}} \mid \mathrm{d}_{1, \mathrm{PL}}\right] \times \mathrm{P}\left[\mathrm{d}_{1}=\mathrm{d}_{1, \mathrm{PL}} \mid \mathrm{I}\right]\right)\right\}
$$

where the weight factor $\mathrm{W}_{\mathrm{PL}}$ is defined for the relative importance of a single performance level. The weight factor could not be used; the resilience index can be calculated with reference to a single PL. The probability for each considered performance level is defined based on the FCs. The considered resilience model links the functionality losses directly to the seismic vulnerability of the building under study. The recovery time $T_{R B}$ and the control time $\mathrm{T}_{\mathrm{LC}}$ are defined based on the damage, the work activities, and the consequent economic resources.

$$
\mathrm{P}\left[\mathrm{d}_{1}=\mathrm{d}_{1, \mathrm{PL}} \mid \mathrm{I}\right]
$$

where $d_{1}$ is the damage sustained by the building and $d_{1, P}$ L I is the considered damage level and corresponding seismic intensity I.

Subsequently, the repair costs $(\mathrm{RC})$ and repair time functions are based on the seismic damage level evaluated above. Conceptually, based on the damage level and the building type, the expected value of the repair cost function for each building type, performance level and seismic intensity is defined as:

$$
\mathrm{E}\left[\mathrm{C}_{\mathrm{r}, \mathrm{r}} \mid \mathrm{d}_{1, \mathrm{PL}}\right]
$$

where $C_{r, r}$ is the relative repair cost; it is evaluated as the ratio of the cost of repairs to the cost of replacing the building. The relationship between the recovery time and the control time is defined as:

$$
\mathrm{E}\left[\mathrm{T}_{\mathrm{RB}} \mid \mathrm{C}_{\mathrm{r}, \mathrm{r}}\right] / \mathrm{T}_{\mathrm{LC}}
$$

Based on this approach, the resilience index is a tool to forecast losses and to address the strategies for an intervention in a practical way.

The proposed resilience index is a conceptual form. Different procedures can be used to evaluate each part of the resilience index. For example, a seismic intensity measurement (I) can help in different ways (macroseismic, peak and integral parameters, etc.). Different damage models can be considered, and so on.

\section{Case Study}

In this section the case study is reported. Based on the Italian and European codes, the main characteristics of geometry, materials, and structural details are reported. The case study is located in Senise (Potenza, Italy). It is a strategic building assigned to the management of the Senise Dam activities. The Senise Dam is a bituminous rock-filled dam located in southern Italy, along the Sinni river. It is made from a simple embankment of well-compacted earth. The Senise Dam was designed and built in the 1970s to sustain the urban, agricultural and industrial water supply in two different regions and in a wide area of southeastern Italy. It is considered the largest earth-filled dam in Europe.

The first step of this investigation was a visual survey on the structure, aimed at identifying the structural system and its dimensions as well as the state of the damages sustained. The global and local state, both of the structure and of the nonstructural elements, is briefly described hereunder. Both the structural and nonstructural elements are not uniformly distributed along the two principal horizontal directions. The buildings under study were designed and constructed in the 1970s, in accordance with the enforced Italian code.

The original design was made without seismic actions. As a matter of fact, the internal beams span in a longitudinal direction only (i.e., where they are needed to support the gravity loads due to the one-way slabs), except for the two external transversal frames that 
bear rigid beams to support the infill panels. In the transversal direction, the columns are weakly connected through very flexible embedded beams.

The original outline construction drawings are available, and they are fully verified in situ; no subsequent modifications were made. The validation of reinforcement details was carried out and it was largely satisfactory. The structural and nonstructural geometry and elements have been surveyed (Figure 1).

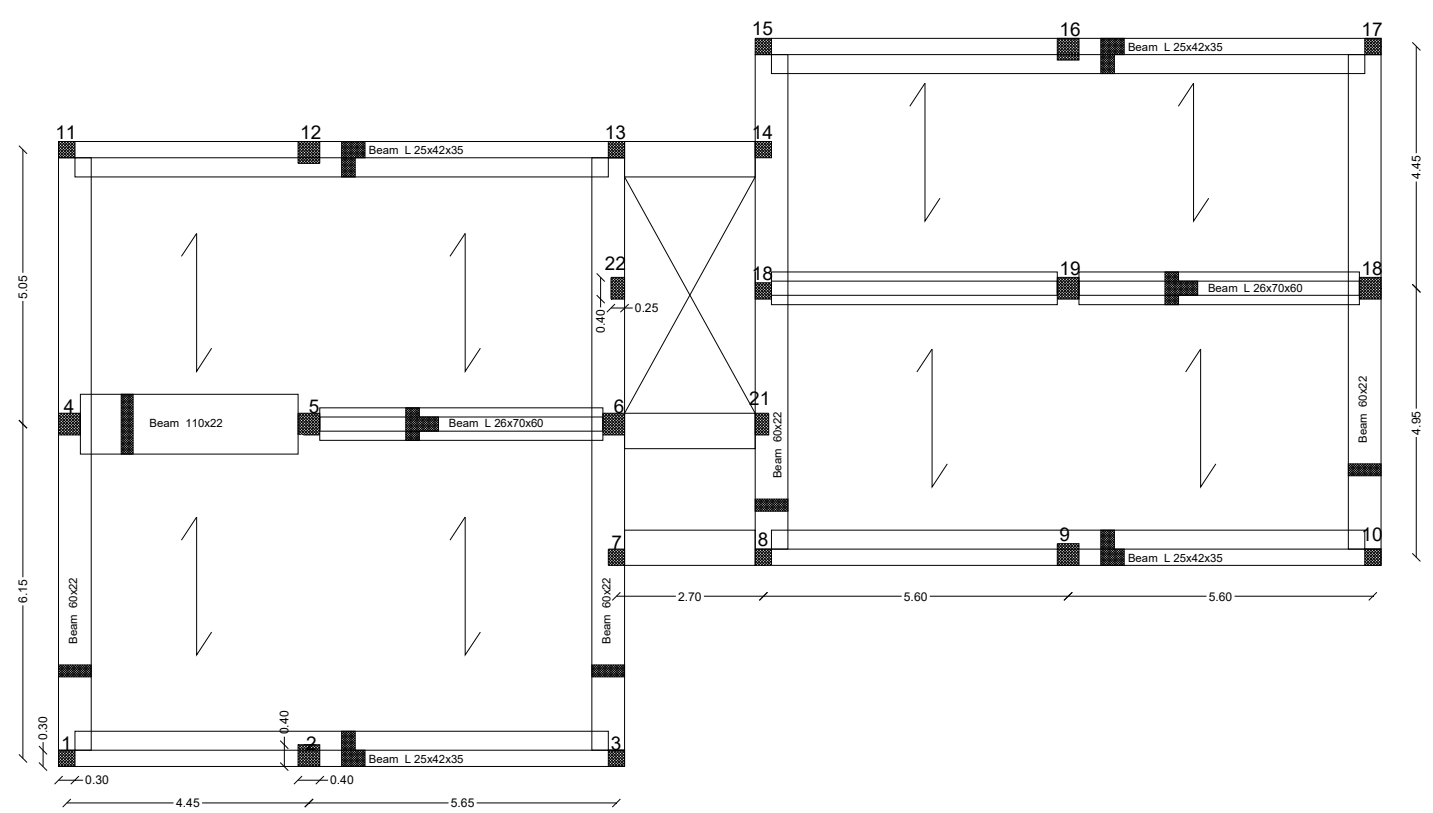

(a)
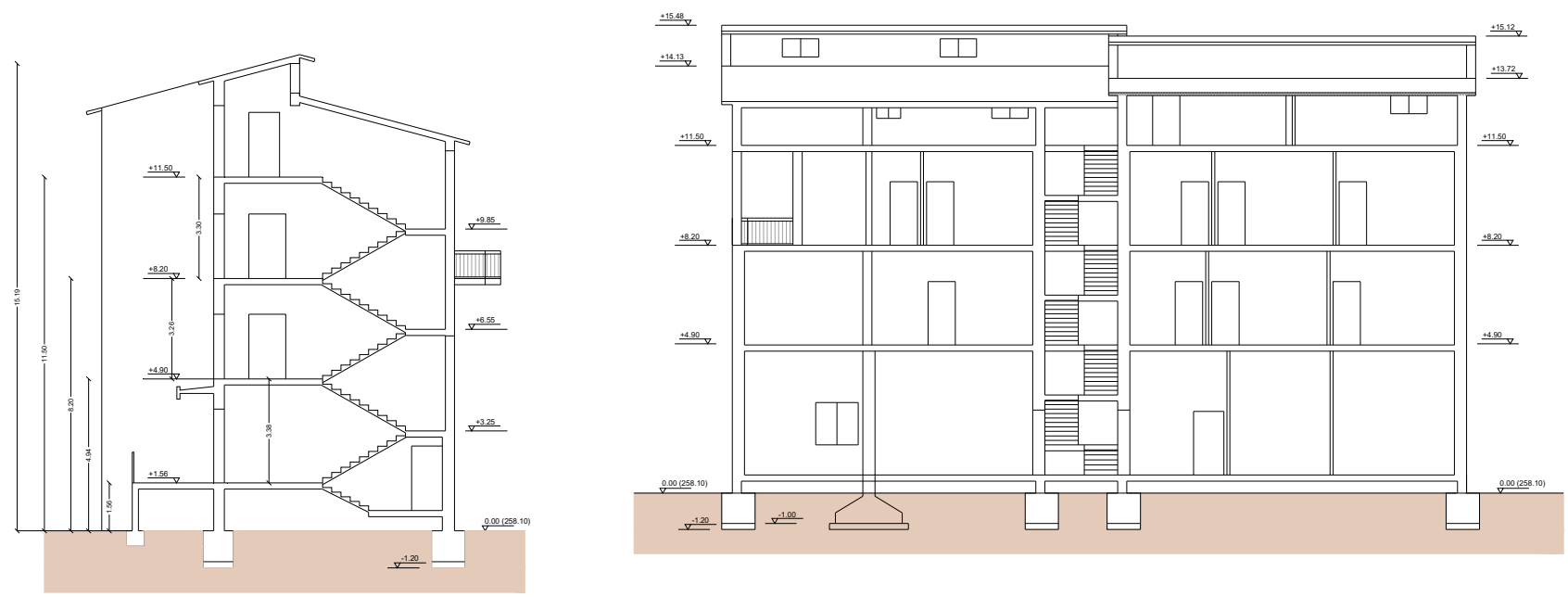

(b)

Figure 1. Case study: (a) plan view; (b) elevation and section view.

The internal beams loaded by the floor slabs have a T section that measures $26 \times 70$ $\times 60 \mathrm{~cm}$. In the external frames the beams have an L section that measures $25 \times 42 \times$ $35 \mathrm{~cm}$. The staircase, centrally placed in the building plan, is made up of inclined beams with a $25 \times 58 \mathrm{~cm}$ section that supports the stair-inclined slabs. Infills are made up of two layers of hollow brick masonry $(15+8 \mathrm{~cm})$. The floors (including the saddle roof) are $\mathrm{RC}$ slabs with a thickness of $22 \mathrm{~cm}$, and thus they can be considered rigid in their own 
plane. The column sizes are variable on each story. On the ground and first story, there are three columns $(30 \times 30 \mathrm{~cm}, 40 \times 40 \mathrm{~cm}, 25 \times 40 \mathrm{~cm})$; on the second and last stories, the columns are $30 \times 30 \mathrm{~cm}, 25 \times 40 \mathrm{~cm}$, and $30 \times 30 \mathrm{~cm}$, respectively. Reinforcement is placed mainly along the shorter side. The building foundation is directly under the first level and it was inspected.

Due to the great importance of the topic, information on the details and mechanical properties of the materials (type, amount and specifications of the reinforcement in the structural members, in situ concrete strength) have been studied. The structural details have been examined, starting from the original outline construction drawings; the amount and layout of the reinforcements, both longitudinal and transversal, and all the structural elements have been verified. An extensive in situ survey and inspection were carried out, based on a direct and instrumental survey [30].

In order to evaluate the mechanical properties of the structural materials (concrete and steel), a wide experimental campaign has been carried out (Table 1). The in situ concrete strength was estimated through destructive tests. Steel, in the deformed bars, was characterized by tension strengths according to the adopted type, which is A38, typically used after 1971 and included in the original design. The characteristic yielding resistance was $\mathrm{f}_{\mathrm{yk}}=380 \mathrm{MPa}$. For the compressive strength of the concrete, standard and mean deviation values are considered in the modeling.

Table 1. Concrete compressive strength: columns and beams.

\begin{tabular}{ccccc}
\hline ID & Level & Element Type & $\begin{array}{c}\text { Unit Weight } \\
\text { Kg/m }\end{array}$ & $\begin{array}{c}\mathbf{f}_{\mathbf{c}} \\
\mathbf{M P a}\end{array}$ \\
\hline 1 & 1 & Column & 2212 & 23.69 \\
2 & 1 & Column & 2212 & 16.53 \\
73 & 1 & Column & 2242 & 23.69 \\
4 & 2 & Column & 2242 & 18.53 \\
5 & 2 & Column & 2126 & 18.55 \\
6 & 2 & Column & 2210 & 20.86 \\
7 & 3 & Column & 2293 & 36.90 \\
8 & 3 & Column & 2210 & 22.83 \\
9 & 2 & Beam & 2142 & 18.32 \\
11 & 2 & Beam & 2228 & 31.41 \\
\hline
\end{tabular}

In the Italian and European codes, the assessment and subsequent retrofit designs are strongly dependent on the amount and quality of the information collected for the structure under examination. The values of the knowledge factors (KFs) are dependent on the actual three knowledge levels (KL) available. Based on the Italian code [31], KL3 was achievable. As a consequence, linear and nonlinear analysis methods, either static or dynamic, could be adopted in the structural evaluation, and a confidence factor (CF) of 1 was used in the safety verifications.

\subsection{Retrofitting Intervention Strategies and Echniques}

In this study, several retrofitting techniques are considered, which are based on strongly different retrofitting strategies. The seismic capacity of the existing RC buildings is based on lateral strength and stiffness. Bearing in mind that a restriction/change of the intended use of the building, or partial demolition thereof, is not possible, and so the improvement of its seismic capacity must be based on the lateral strength and stiffness. These requirements can be obtained with (i) the local retrofitting of existing elements, (ii) increasing lateral resistant systems with new structural elements (for example with concrete walls, concrete or steel moment frames or steel braced frames), or (iii) passive protection devices (dissipative bracing or base isolation). Obviously, the techniques taken into account should be considered as examples of practice applications whose design 
details cannot be generalized. All considered retrofitting techniques are based on the total upgrade of the building, and are to be compliant with the current building code [31,32].

\subsubsection{Concrete Jackets (CJ)}

The first option is based on the retrofitting of existing elements and entails increasing the sizes of columns and beams. This retrofitting technique is applied in order to increase the resistance and deformation capacities (flexural and shear) of the retrofitting elements. It is applied to columns and some beams, where the thickness of the jackets is defined according to the placements of both the longitudinal and transversal reinforcements. To reach the retrofitting goals, longitudinal reinforcements (steel bars) are continued between the stories, and the ties are placed in the beam-column joints. This retrofitting technique is widely used and is reported in the versions of the current codes (both Italian and European).

\subsubsection{RC Walls (RCW)}

The goal of the second retrofitting technique is to increase the lateral strength with a new structural system. The design is based on both the existing and the new structural elements (e.g., Reinforced Concrete walls, RC walls) so as to satisfy the requirements of the codes [31] in terms of lateral strength and stiffness.

The position of the new RC walls is designed to optimize lateral stiffness and strength, as well as to reduce the stresses and displacements on the existing structural elements. The final layout is defined to minimize the impact on the existing buildings and optimize the construction of new foundations. The existing columns are incorporated into the new RC walls and all the existing structural elements are connected with the new RC walls. This technique is applied only on the external frame without affecting the internal structural and nonstructural elements.

\subsubsection{RC Walls and Steel Jackets (RCW-SJ)}

The goal of the third retrofitting technique is based on the second technique, and also entails increasing the resistance and deformation capacities (flexural and shear) of the structural elements without increasing their size. This technique requires the retrofitting of the external and internal frames and single structural elements. The design is based on both the existing retrofitting elements and the new structural elements. Steel jackets are applied to columns and beams. Commonly, steel jackets are also applied so as to increase the shear strength and improve the strength of deficient lap-splices. In this study, this technique is also implemented to increase flexural strength; longitudinal reinforcement is continued between the stories (for column) and between the different beams. Moreover, the significant effect of the confinement is considered to increase the concrete strength. Operationally, the technique is applied using four corner angles for the columns and beams with transversal welded steel straps. The thickness of the jackets is based on the design requirement for reinforcing the structural elements. This retrofitting technique is widely applied and is reported in the versions of the current codes (both Italian and European).

\subsubsection{Seismic Isolation System (SIS)}

The fourth technique is based on the passive protection devices. This structural intervention is defined considering a base-isolation system, with elastomeric (i.e., HDRB) and sliding (i.e., steel-PTFE) bearings. The isolation devices are located at the foundation level (Figure 2). The resulting superstructure is a building with four stories above ground, and the structural system thus obtained is completely modified into a more compatibly seismic-proof building. The described configuration of the isolation system is defined to provide the required deformability and avoid the torsional effects. The modal response spectrum analysis is incorporated into the retrofitting analysis and the design of the isolation systems. Coherent with the function of investigating the building, the design goal does not damage the building's superstructure. 
Understanding the collapse behavior of existing buildings retrofitted with seismic isolation is still a work in progress [33].

In this study, regarding the definition of the collapse condition of a seismic isolation system, it occurs at a seismic intensity that is higher than those associated with the parameters of the design earthquake; the building's superstructure maintains its elastic behavior.

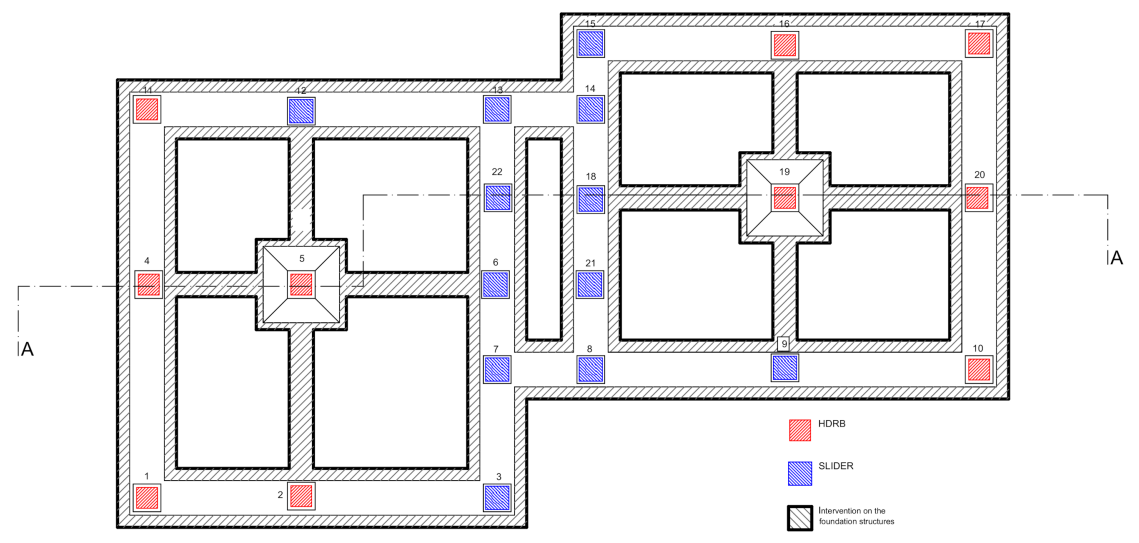

Figure 2. Plan view of the isolation system's configuration.

\subsection{Analysis of the Nonlinear Seismic Behavior and Fragility Curves}

The fragility assessment of a building is carried out to achieve the goals of this study. The existing buildings and all the different schemes of the retrofitted buildings are modeled with SAP 2000 V21 [34]. This software is selected for its characteristics and for its widespread use among professionals. In order to evaluate the seismic response of the case study, a nonlinear model is defined. Frame objects are used to model beams, columns, and truss elements in 3D systems. Nonlinearity is modeled through the assignment of frame hinges. Other codes, perhaps more reliable but also more complex to use, have been excluded.

Dead and live gravity loads and a system of lateral seismic forces were applied follow the Italian code provision. The code provision is based on at least two vertical distributions of lateral loads: (i) a uniform pattern (proportional to the masses at each story) and (ii) a modal pattern (proportional to the mass matrix and modal shape). Consequently, lateral forces were applied at the mass center of each floor, considering eccentricity $(5 \%)$ due to the nonuniform distribution of the loads and non-synchronism of the seismic action.

A nonlinear static analysis is considered in all cases and input parameters are briefly reported. Each numerical analysis is based on the same evaluation of:

- the gravity loads and their combination with the seismic load following the code provision;

- plastic hinges for columns and beams based on their flexural and shear capacities;

- ductile and brittle structural elements are considered in plastic hinges and verification is checked in terms of the corresponding deformation capacities;

- infill panels are considered and modeled with only their axial compressive plastic hinges;

- for each case, structural limit states of immediate occupancy (PL1) and collapse prevention (PL4) are considered.

The results of the assessment procedure show the criticality of the building. It has a low capacity in the first story, where the shear strength of the staircase column and the inter-story height make it very vulnerable.

In the existing RC structures, structural members could show a flexural or brittle shear failure. Consequently, the structural performance can be predicted based on the plastic hinge according to the material characteristics and the cross-section details. The considered details for plastic hinges are based on the analytical backbone of the structural 
and nonstructural elements. The flexural and shear capacities for beams and columns are considered.

The properties of the plastic hinges have been defined according to the dimensions, details, and mechanical properties of each structural and nonstructural element. In this work, the simplified approach suggested in previous studies $[35,36]$ has been taken into consideration. In fact, the shear failure is generally considered to be a brittle mechanism. Actually, two different behaviors should be considered: brittle shear and ductile shear. Brittle shear failure (Figure 3a) is dependent only on the shear strength. Ductile shear failure (Figure $3 \mathrm{~b}$ ) can be computed based on the intersection point of the flexural and shear behavior (Figure 3c).

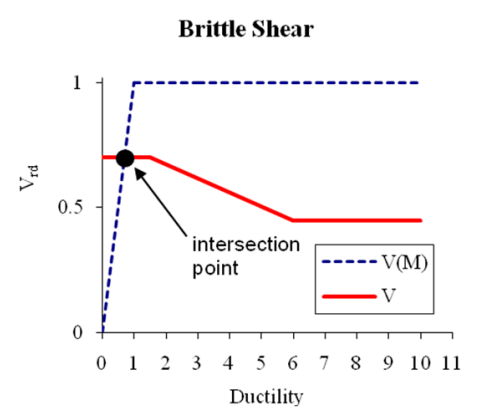

(a)

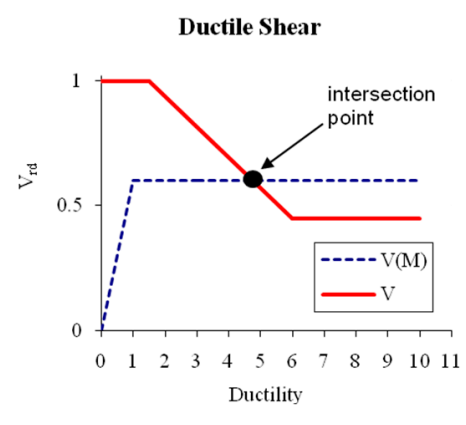

(b)

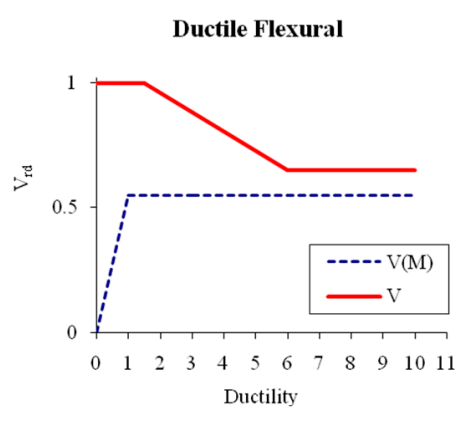

(c)

Figure 3. Case study: (a) plan view; (b) elevation and section view (c).

The damage levels considered are clearly connected with the PLs deliberated on by the Italian [31] and European [32] codes, namely, operative PL, limited (or light) damage PL, life safety PL, and collapse PL. Each damage level is characterized by a quantitative description based on the nonlinear status of the structural elements, in agreement with the code provision. Synthetically, Figure 4 shows the structural element performance required by each damage level. The structural performances are assessed using local parameters (the ductility ratio of beams and columns). Then, the structural performances are linked to the global damage level using a specific damage model [6], as reported in Figure 4.

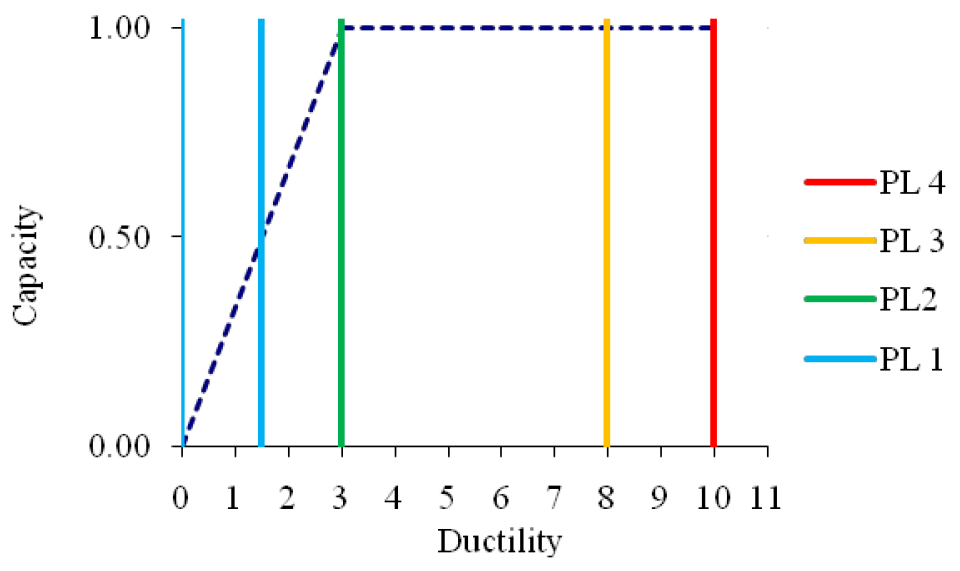

Figure 4. Relationship between plastic hinges (moment rotation curve) and performance levels.

For the infill panels, truss elements are used only for the axial compressive forces. Axial force-axial displacement hinges are based on infill panels' characteristics. The maximum resistance of a truss model is based on material properties. Elastic-plastic hinges are considered, which are defined by means of the yielding point, maximum strength and ultimate displacement point of the truss element based on the drift $(1.25 \%$ and $5 \%$ ). 
Based on a nonlinear static analysis, the PLs have been assessed considering the current state, and each retrofitting technique uses a nonlinear static analysis method. The building model is a 3D model. Internal diaphragm constraints have been assigned to all nodes of the same floor to consider the effective stiffness of the floors.

Based on the PL and consequent damage level, initial yielding, immediate occupancy, life safety, and collapse prevention for each damage level considered, the capacity of the structural and nonstructural elements is evaluated. The maximum interstorey drift ratio (IDR) has been evaluated and considered as an engineering demand parameter (EDP). In Figure 5, 3D models are shown while in Figure 6, the obtained capacity curves are reported.

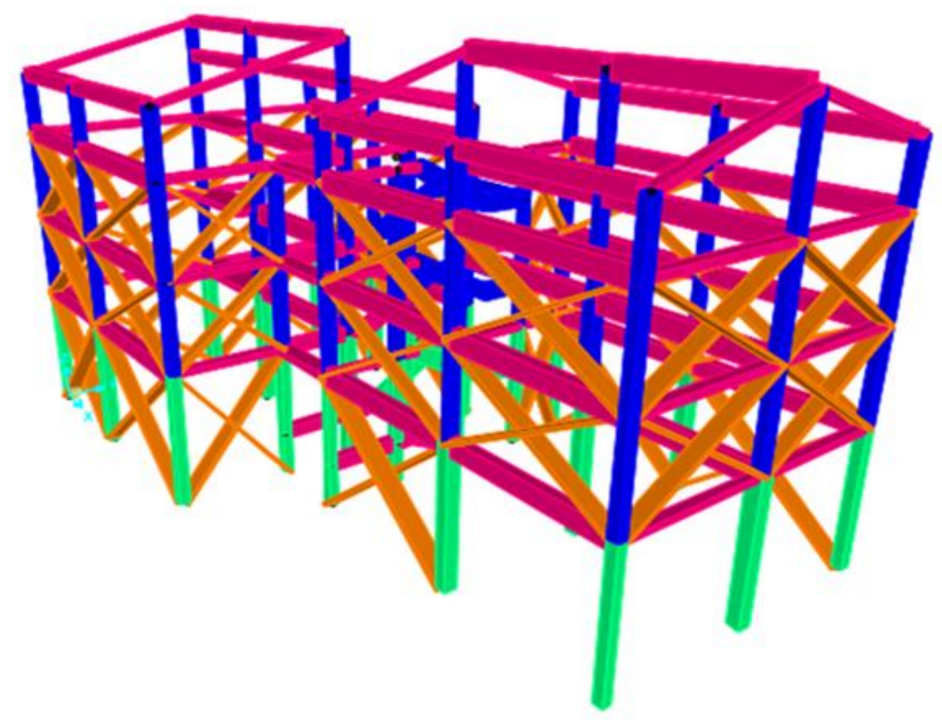

Figure 5. A 3D model of the building under study (current state).

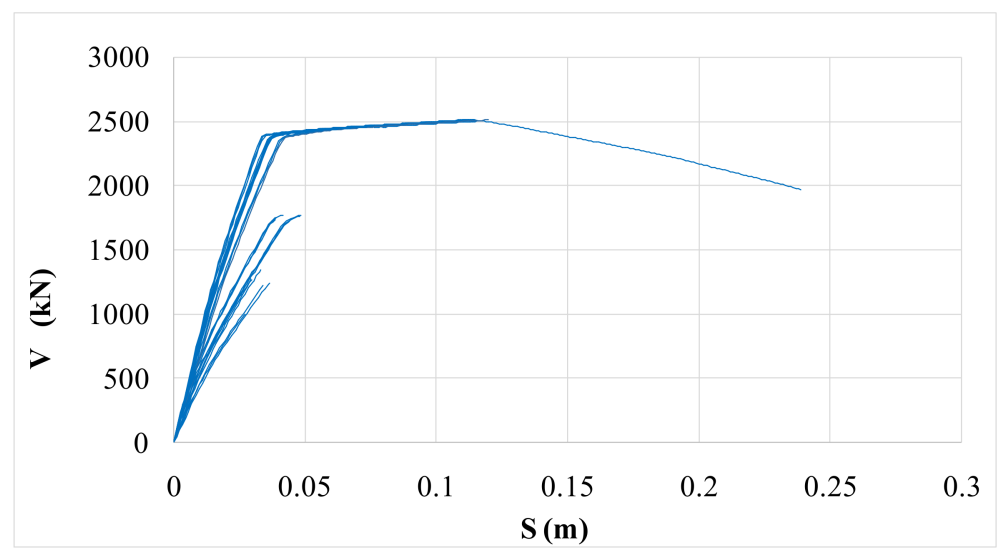

Figure 6. Capacity curves (Base shear V-Roof displacement S) of the building under study (current state, longitudinal and transversal direction).

For the ground motion intensity measure (IM), the peak ground acceleration (PGA) is considered so as to be consistent with the code hazard. Thus, for the building under study (in its current state and with the retrofitting techniques used), the fragility curves are defined. Fragility curves are defined following the procedure proposed by several authors [6]. Based on the results of the analyses, the capacity curves are thus obtained and consequently built for each single degree of freedom (SDoF) system. For the selected ground motions, these bilinear, elastic and perfectly plastic curves are used to represent the effects of a record-to-record variability. The structural performances of the building types were evaluated using 50 natural accelerograms (Figure 7) that were selected following the previous study [37]. With regard to the data used for the earthquake hazard analysis, the 
site effects are not taken into consideration, even though they could play a significant role in the damage sustained [38]. Nevertheless, in this case, they can be neglected: the building is located on artificial and controlled soil.

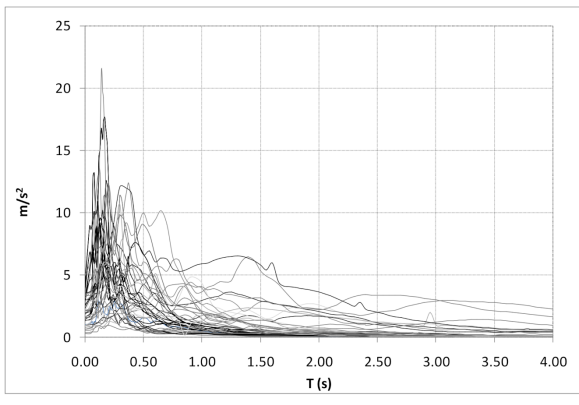

(a)

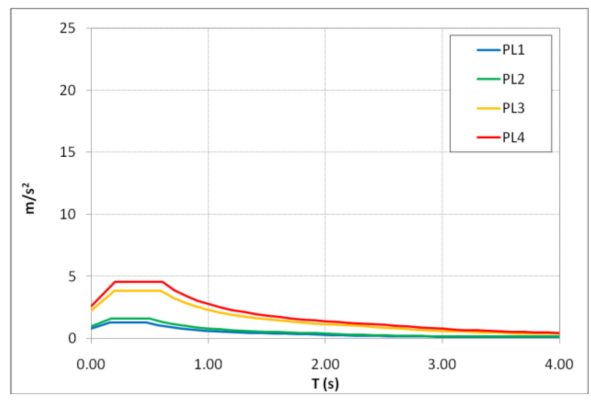

(b)

Figure 7. Elastic spectra of the considered records (a) and PL spectra code (b). Here, the elastic spectra derived from the code for the building under study are reported.

FCs were defined using the well-known procedures based on cumulative distribution functions (CDF). The FCs are based on the form:

$$
\mathrm{P}\left[\mathrm{d}_{\mathrm{PL}} \mid \mathrm{PGA}\right]=\Phi\left[\frac{1}{\beta_{d_{P L}}} \times \ln \left(\frac{\mathrm{PGA}}{\mu_{\mathrm{PL}}}\right)\right]
$$

where $\mu_{\mathrm{PL}}$ is the median value of the seismic intensity; $d_{\mathrm{PL}}$ describes the performance level; $\beta_{d_{P L}}$ is the standard deviation of the natural logarithm of the seismic intensity; $\Phi$ is the standard normal cumulative distribution function.

In order to obtain a brief and easy-to-understand application of this work, only a few details and results are reported. Lastly, the fragility curves are built using a common statistical curve fitting approach; the resulting fragility curves are shown in Figure 8.

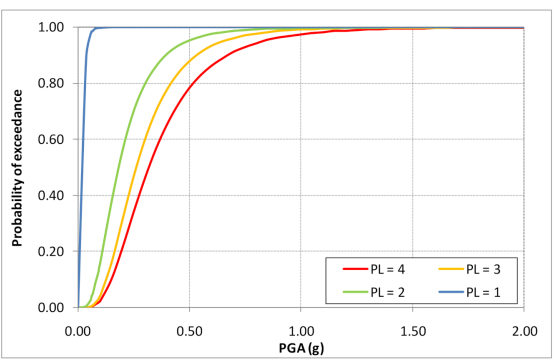

(a)

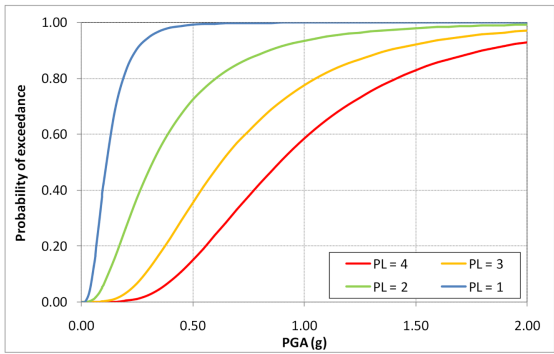

(c)

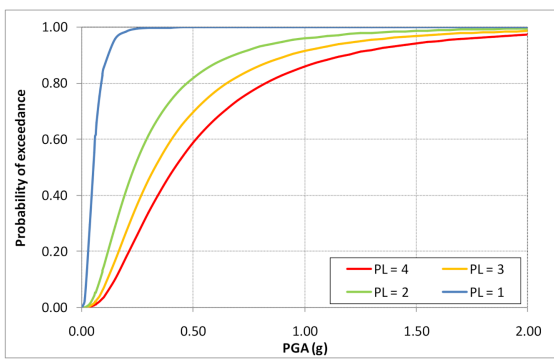

(b)

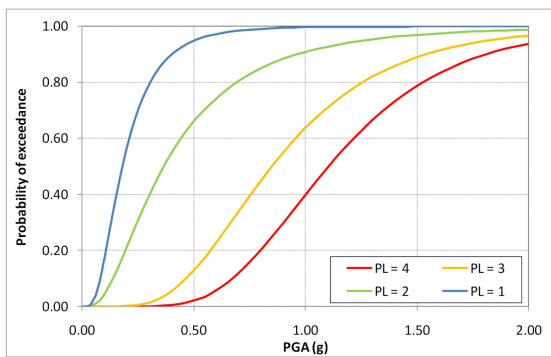

(d)

Figure 8. Fragility curves of the building under study, in its current state (a) and with different retrofitting techniques: concrete jackets $(\mathrm{CJ})(\mathbf{b}), \mathrm{RC}$ walls $(\mathrm{RCW})(\mathbf{c})$, and $\mathrm{RC}$ walls and steel jackets (RCW-SJ) (d). 
As expected, the behaviors of the retrofitted buildings are significantly different, particularly for PL1 and PL4. For the RCW and RCW-SJ retrofitting techniques, the differences are due to the different degrees of rigidity in the walls and the capacities of the retrofitted structural elements.

Specific cost ratio values have been defined as derived from the damage distribution for each performance level. In this way, the damage distribution of the buildings has been investigated with effective tools that are related to the performance of each structural or nonstructural element according to its repair costs, which include the materials used for the repairs, cost formulations, social-economic work conditions, etc. In general, nationalregional price lists already take into account these sources of uncertainty, providing average cost values. Moreover, the effects of the repair costs related to all preliminary, secondary, and supplementary works must be considered. The cost ratio $C_{r, r}$ is defined as the ratio between the overall costs needed to restore pre-earthquake conditions and the costs to replace the building (including the demolition costs). The cost ratio can vary from 0 to 1. This parameter is more useful in determining the relative importance of the repair activities than in measuring the importance of the demolition and reconstruction activities. Furthermore, cost ratios are useful for the evaluation of the economic convenience of the total repair, reconstruction and retrofitting strategies.

The considered retrofitting techniques have very different costs (Figure 9), different levels of fragility, and consequently different seismic losses. Subsequently, the proposed approach can identify the optimal strategies based on costs, total investment amounts, and the performance levels that are acceptable for the policy makers.

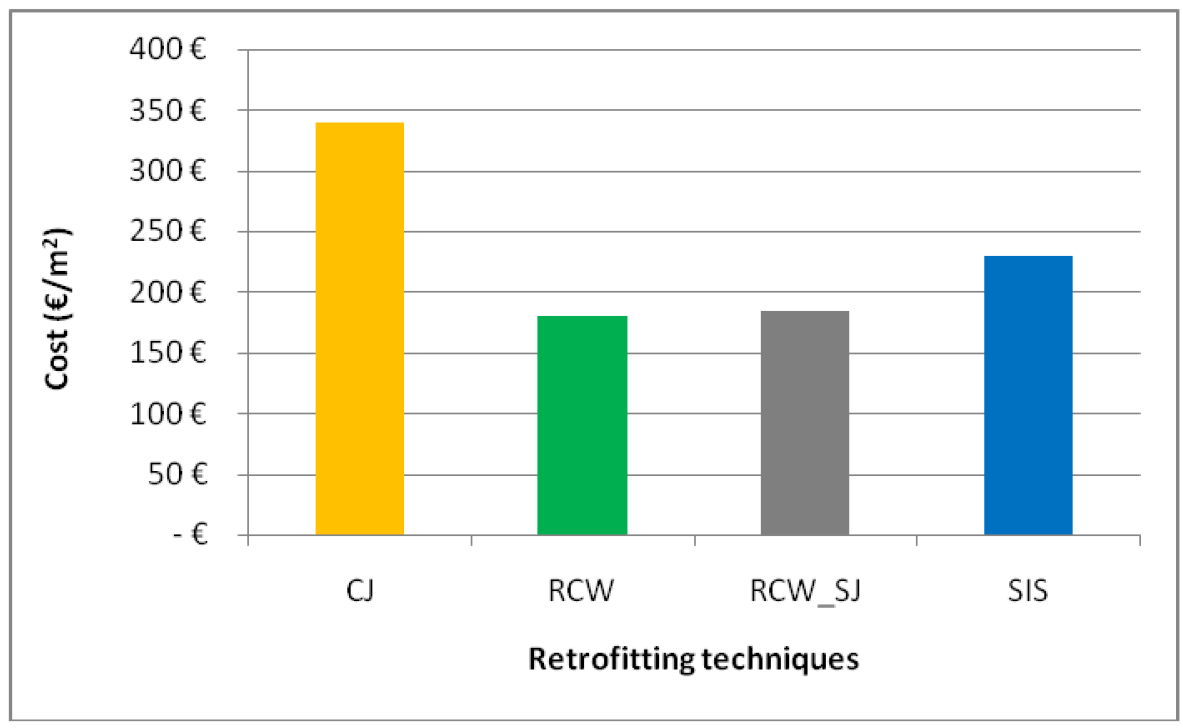

Figure 9. Cost for different retrofitting techniques.

\section{Analysis of the Results}

In this section, the results of the proposal and the resilience-based comparison for the considered retrofitting techniques are reported. For the considered performance level, the fragility curves for the current state and for the considered retrofitting techniques applied to the existing building are shown. The FCs represent a quantitative evaluation of Equation (2). Each value of the FCs measures the probability of occurrence for each performance level. Equation (2) can be considered null for the fourth technique, which is seismically adequate and which complies with the seismic standards until the collapse of the seismic isolation structure.

Based on the resilience index (Equation (1)), the current state and the four considered alternative retrofitting techniques are compared. Thus, the proposed resilience index is evaluated via a vulnerability analysis that can be considered a more realistic approach. 
For each considered performance level of the structural and nonstructural elements, the mean values of the repair costs have been evaluated. A virtual process of repair and strengthening interventions has been defined following the current practices of design and economic computations derived from professional practices. The values of the response parameters have been evaluated within a set of repair activities, costs, and consequently required intervention and working times. The repair activities have been selected in accordance with the most widespread and typical techniques. They resulted from the post-earthquake reconstruction process in L'Aquila, and subsequent economic and temporal evaluations.

The global cost of the repairs for the buildings in their current states and for each retrofitting technique has been defined starting from the damage of each individual structural and nonstructural component. Consequently, the global repair cost has been regulated considering the cost of the reconstruction. The recovery time is defined considering the down-time and the repair time. The last part of the resilience index (Equation (4)) is evaluated.

The recovery time is defined based on the inactivity time (pseudo-horizontal phase) and the repair activities (recovery time). The inactivity time is, in turn, evaluated based on the existing post-earthquake data and the specific evaluation of the strategic role of the investigated building. The inactivity time and recovery time depend on the considered performance level. The repair activities are evaluated in accordance with the repair and retrofitting techniques contemplated, and are evaluated based on the current prospectus for the Basilicata region. Consequently, the functionality curve is defined considering the building with a low damage level and higher damage levels. The considered control times are respectively $\mathrm{T}_{\mathrm{LC}}=120$ days and $\mathrm{T}_{\mathrm{LC}}=300$ days. Lastly, the resilience performance of the investigated building and the considered retrofitting techniques are evaluated, as reported in Figure 10.

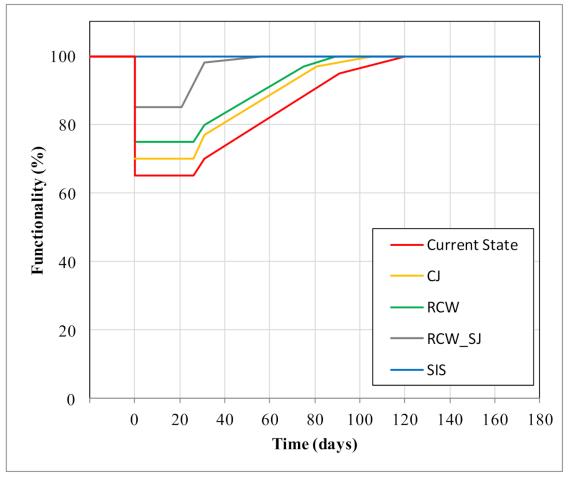

(a)

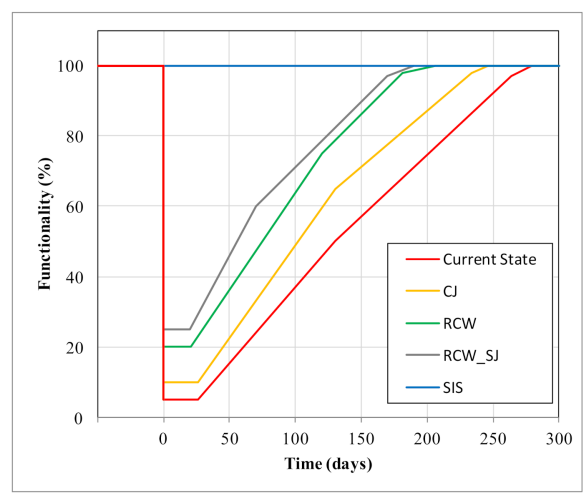

(b)

Figure 10. Resilience curves of the building under study, in its current state and with retrofitting techniques for PL1 (a) and PL4 (b).

As shown in Figure 9, the resilience index strongly depends on the considered performance level and on the retrofitting techniques. In the current state, long recovery times must be considered, but (based on the historical data and repair costs and times) the recovery times seem to be brief, depending on the retrofitting techniques, except for the seismic isolation system that is designed not to be damaged.

This result was expected. In fact, if the fragility analysis shows a markedly different behavior, the loss of functionality depends on the nonstructural elements (destroyed for PL4) and on the secondary structural elements (for example, stair beams). Consequently, the costs and recovery times are quite similar. Conversely, for the base-isolation system, the design strategy excludes any damage done to the structural and nonstructural elements. In effect, it is to be highlighted that each retrofit technique is based on the total upgrade of the building, and is to be compliant with the current building code. Nevertheless, they are not necessarily resilient strategies. 
Based on a numerical evaluation, the results highlight that the resilience index (Table 2) is able to select the most resilient strategies. Moreover, the improvement in the resilience of the retrofitted building is quantitatively evaluated. The resilience index values are a first step towards obtaining an effective cost-benefit evaluation, overcoming the simple cost-benefit. This is a significant improvement and can be validly and widely applied in other frameworks, for example in those based on a multidisciplinary approach (i.e., MCDM approach).

Table 2. Effects of different retrofitting techniques: resilience index for PL1 and PL4.

\begin{tabular}{cccccc}
\hline & $\begin{array}{c}\text { Current State } \\
\text { CS }\end{array}$ & $\begin{array}{c}\text { Concrete Jackets } \\
\text { CJ }\end{array}$ & $\begin{array}{c}\text { RC Walls } \\
\text { RCW }\end{array}$ & $\begin{array}{c}\text { RC Walls and } \\
\text { Steel Jackets } \\
\text { RCW_SJ }\end{array}$ & $\begin{array}{c}\text { Seismic } \\
\text { Isolation System } \\
\text { SIS }\end{array}$ \\
\hline PL1 & 0.739 & 0.810 & 0.865 & 0.965 & 1 \\
PL4 & 0.501 & 0.605 & 0.677 & 0.733 & 1 \\
\hline
\end{tabular}

\section{Conclusions and Work in Progress}

The core of the study is a resilience approach to the seismic retrofitting of existing strategic buildings. The resilience is evaluated for different performance levels and is thus quantified. In this study, the effects of the different retrofitting strategies of strategic buildings are studied and compared. The resilience index is considered for the selection of the optimal intervention options. It is based on previous studies and proposals, and it can be used on different territorial scales and systems.

In the proposed resilience index, different performance levels are considered, and four strongly different retrofitting techniques are compared according to their fragility and post-earthquake cost and time recovery analyses. In order to select the optimal solution, technical, economic, and practice procedures are considered. Consequently, the decision to choose the optimal retrofitting techniques and strategies is made by comparing the evaluated resilience index. This is related to the expected reduction in seismic losses due to different retrofitting techniques, but especially to the effectiveness of the intervention based on the relevant cost and recovery times. In other words, these aspects take into account the key role of a building's characteristics, and the public and strategic role during and after the earthquakes. The intervention is selected not only (as is currently done) to reduce its construction times and costs, but is also considered to limit the service interruption after earthquakes.

Compared to existing procedures and practices, the seismic risk mitigation, the costs, and the effectiveness in guaranteeing strategic functions, are quantitatively evaluated based on technical and rigorous procedures. More specifically, the economic convenience of different retrofitting techniques is not considered as a fundamental factor.

Fragility and vulnerability analyses, defined according to the capacity of structural and nonstructural elements and their repair costs due to a seismic event, are influenced by the recovery times. Strong differences in the fragility analyses cannot be significant in terms of functionality. On the contrary, if selected based only on the fragility and vulnerability analyses, the selection of the optimal retrofitting techniques could be misleading.

The new contributions of the study are:

- The improvement of the existing methodologies for the optimal selection of retrofitting intervention strategies.

- The clear and quantitative consideration of: economic and technical convenience, structural safety and continuity of use of buildings (public safety and civil protection, integrity during and after earthquakes).

- Real and practical application of the resilience concepts, both for decision makers and for the practice of professional applications.

The results of this study could be operatively used as support tools in the seismic retrofitting of strategic buildings, individually or on a large territorial scale. 
Author Contributions: Conceptualization, M.V.; methodology, M.V.; formal analysis, M.V., E.C., A.F. and E.F.; data curation, M.V.; writing-original draft preparation, M.V. and A.F.; writing-review and editing, M.V. and A.F. All authors have read and agreed to the published version of the manuscript.

Funding: This research was partially funded by: (i) "Study for the retrofitting strategies for dam control building using innovative approach", E.I.P.L.I. (Italy), School of Engineering (University of Basilicata) cooperation agreement; (ii) 2020 MIUR PON R\&I 2014-2020 Program (project MITIGO, ARS01_00964).

Data Availability Statement: The study reported no data, links to publicly archived datasets analyzed or generated during the study.

Acknowledgments: No external acknowledgments are needed in this study.

Conflicts of Interest: The authors declare no conflict of interest.

\section{References}

1. Cimellaro, G.P. New trends on resiliency research. In Proceedings of the 16th World Conference on Earthquake Engineering, 16WCEE 2017, Santiago, Chile, 9-13 January 2017.

2. Vona, M.; Harabaglia, P.; Murgante, B. Thinking about resilience cities studying Italian earthquake. Urban. Des. Plan. 2016, $169,185-199$.

3. Dolce, M.; Di Bucci, D. Comparing recent Italian earthquakes. Bull. Earthq. Eng. 2015, 15, 497-533. [CrossRef]

4. Applied Technology Council. Seismic Performance Assessment of Buildings; FEMA P-58-1; Applied Technology Counci: Redwood City, CA, USA, 2012.

5. Calvi, G.M. Choices And Criteria For Seismic Strengthening. J. Earthq. Eng. 2013. [CrossRef]

6. Vona, M.; Manganelli, B.; Tataranna, S.; Anelli, A. An optimized procedure to estimate the economic seismic losses of existing reinforced concrete buildings due to seismic damage. Buildings 2018, 8, 144. [CrossRef]

7. Vona, M. A novel approach to improve the code provision based on a seismic risk index for existing buildings. J. Build. Eng. 2020, 28, 101037. [CrossRef]

8. Ministerial Decree 58/2017. Sisma Bonus—Linee Guida per la Classificazione del Rischio Sismico delle Costruzioni Nonché le Modalità per L'attestazione, da Parte di Professionisti Abilitati, Dell'efficacia Degli Interventi Effettuati; Ministero delle Infrastrutture e dei Trasporti: Rome, Italy, 2017. (In Italian)

9. Caterino, N.; Cosenza, E. A multi-criteria approach for selecting the seismic retrofit intervention for an existing structure accounting for expected losses and tax incentives in Italy. Eng. Struct. 2018, 174, 840-850. [CrossRef]

10. Anelli, A.; Vona, M.; Hidalgo, S.S.C. Comparison of different intervention options for massive seismic upgrading of essential facilities. Buildings 2020, 10, 125. [CrossRef]

11. Bruneau, M.; Chang, S.; Eguchi, R.; Lee, G.; O’Rourke, T.; Reinhorn, A.M.; Shinozuka, M.; Tierney, K.; Wallace, W.; Winterfelt, D. A framework to Quantitatively Assess and Enhance the Seismic Resilience of Communities. Earthq. Spectra 2003, 19, 733-752.

12. Bruneau, M.; Reinhorn, A. Exploring the concept of seismic resilience for acute care facilities. Earthq. Spectra 2007, 23, 41-62. [CrossRef]

13. Cimellaro, G.; Fumo, C.; Reinhorn, A.; Bruneau, M. Quantification of Disaster Resilience of Health Care Facilities; MCEER-09-0009; MCEER: Buffalo, NY, USA, 2009.

14. Applied Technology Council. Here Today-Here Tomorrow, The Road to Earthquake Resilience in San Francisco, Community Action Plan for Seismic Safety; ATC-52-2 Report; Applied Technology Council: Redwood City, CA, USA, 2010.

15. Burton, H.V.; Deierlein, G.; Lallemant, D.; Singh, Y. Measuring the Impact of Enhanced Building Performance on the Seismic Resilience of a Residential Community. Earthq. Spectra 2017. [CrossRef]

16. Kammouh, O.; Dervishaj, G.; Cimellaro, G.P. Ideal Resue. Resilience assessment at the state level. In Proceedings of the 1st International Conference on Natural Hazards \& Infrastructure, Chania, Greece, 28-30 June 2016.

17. Zobel, C.W. Representing perceived tradeoffs in defining disaster resilience. Decis. Support. Syst. 2011, 50, 394-403. [CrossRef]

18. Alipour, A.; Shafei, B. Seismic resilience of transportation networks with deteriorating components. J. Struct. Eng. 2016, 142, 1-12. [CrossRef]

19. Chandrasekaran, S.; Banerjee, S. Retrofit optimization for resilience enhancement of bridges under multihazard scenario. J. Struct. Eng. 2013, 1, 1-12. [CrossRef]

20. Chang, S.E.; McDaniels, T.; Fox, J.; Dhariwal, R.; Longstaff, H. Toward Disaster-Resilient Cities: Characterizing Resilience of Infrastructure Systems with Expert Judgments. Risk Anal. 2014, 34, 416-434. [CrossRef]

21. Paidakaki, A.; Moulaert, F. Does the post-disaster resilient city really exist? A critical analysis of the heterogeneous transformative capacities of housing reconstruction 'resilience cells'. Int. J. Disaster Resil. Built Environ. 2017, 8. [CrossRef]

22. Vona, M.; Mastroberti, M.; Mitidieri, L.; Tataranna, S. New resilience model of communities based on numerical evaluation and observed post seismic reconstruction process. Int. J. Disaster Risk Reduct. 2018, 28, 602-609. [CrossRef]

23. Vona, M. Proactive actions based on a resilient approach to urban seismic risk mitigation. Open. Constr Build. Technol. J. 2020, 14, 321-335. [CrossRef] 
24. Samadian, D.; Ghafory-Ashtiany, M.; Naderpour, H.; Eghbali, M. Seismic resilience evaluation based on vulnerability curves for existing and retrofitted typical RC school buildings. Soil Dyn. Earthq. Eng. 2019, 127, 105844. [CrossRef]

25. Anelli, A.; Santa-Cruz, S.; Vona, M.; Tarque, N.; Laterza, M. A proactive and resilient seismic risk mitigation strategy for existing school buildings. Struct. Infrastruct. Eng. 2019, 15, 137-151. [CrossRef]

26. Wein, A.; Rose, A.Z. Economic Resilience Lessons from the Shake Out Earthquake Scenario. Earthq. Spectra 2011, 27, 559-573 [CrossRef]

27. Bal, E.I.; Crowley, H.; Pinho, R.; Gulay, G.F. Detailed Assessment of structural characteristic of Turkish RC building stock for loss assessment models. Soil. Dyn. Earthq. Eng. 2008, 28, 914-932. [CrossRef]

28. ATC-Applied Technology Council. Next-Generation Seismic Performance Assessment for Buildings; FEMA P-58; Implementation Guide Federal Emergency Management Agency: Washington, DC, USA, 2012.

29. Borzi, B.; Vona, M.; Masi, A.; Pinho, R.; Pola, D. Seismic demand estimation of RC frame buildings based on simplified and nonlinear dynamic analyses. Earthq. Struct. 2013, 4, 157-179. [CrossRef]

30. Masi, A.; Vona, M. La stima della resistenza del calcestruzzo in-situ: Impostazione delle indagini ed elaborazione dei risultati. Progett. Sismica 2009, 1, 53-67.

31. Norme Tecniche per le Costruzioni. Ministerial Decree. Gazzetta Ufficiale della Repubblica Italiana; Ministero delle Infrastrutture, Supplemento Ordinario n. 30; Istituto Poligrafico e Zecca dello Stato: Rome, Italy, 2018. (In Italian)

32. Design of Structures for Earthquake Resistance, Part 3, Assessment and Retrofitting of Buildings; EN 1998-3-1-4, Eurocode 8; European Committee for Standardization: Bruxelles, Belgium, 2005.

33. Flora, A.; Perrone, G.; Cardone, D. Evaluating Collapse Fragility Curves for Existing Buildings Retrofitted Using Seismic Isolation. Appl. Sci. 2020, 10, 2844. [CrossRef]

34. CSI. Analysis Reference Manual for SAP2000®, ETABS®and SAFE ${ }^{\mathrm{TM}}$; Computers and Structures, Inc.: Berkeley, CA, USA, 2005; 415p.

35. Mpampatsikos, V.; Nascimbene, R.; Petrini, L. A critical review of the R.C. frame existing building assessment procedure according to eurocode 8 and Italian seismic code. J. Earthq. Eng. 2008, 12, 52-82. [CrossRef]

36. Masi, A.; Vona, M.; Manfredi, V. A parametric study on RC existing buildings to compare different analysis methods considered in the European seismic code (EC8-3). In Proceedings of the 14th World Conference on Earthquake Engineering, Beijing, China, 12-17 October 2008.

37. Masi, A.; Vona, M.; Mucciarelli, M. Selection of Natural and Synthetic Accelerograms for Seismic Vulnerability Studies on Reinforced Concrete Frames. J. Struct. Eng. 2011, 137, 367-378. [CrossRef]

38. Puglia, R.; Vona, M.; Klin, P.; Ladina, C.; Masi, A.; Priolo, E.; Silvestri, F. Analysis of site response and building damage distribution induced by the 31 October 2002 earthquake at San Giuliano di Puglia (Italy). Earthq. Spectra 2013, 29, 497-526. [CrossRef] 